\title{
Inclusion and Repression of Animal Figures in the Short Fiction of Chekhov and Bangdel
}

\author{
Saroj Koirala \\ Professor of English, Prithvi Narayan Campus, \\ Tribhuvan University, Pokhara, Nepal
}

\section{Animals in Literature}

Fiction is largely a domain of human beings having anthropocentrism as its organizing principle. However, the genre sometimes employs non-human animals too as characters which can be viewed as an innovative tool of modern narratology. Through the use of de-anthropomorphized characters such works provide space for an interpretation of animal behavior and their consciousness.

Universally, human beings have kept companion pets as domestic animals are believed to be sentient beings compared to wild ones. For instance, archeological records of 15 millenniums have reported that dogs used to live together with humans because of their faithful companionship. Animals, therefore, abound in literature across all ages and cultures, but only rarely have they been the focal point of systematic literary study (McHugh 487). As a result, more recent literary criticism has focused on the ethics and the politics of human-animal bonds (HAB), animal communication, animal emotion and so on.

\section{Chekhov's "Misery"}

The short story is set in an evening of the late 19th century St. Petersburg city of Russia. Iona Potapov - a poor, old, and companionless coach driver-has recently lost his only son and he is fully agonized. He hopes that his heart might be relieved if he narrates about the death and funeral procession to someone. Despite his several endeavors Iona finds no human ear willing to listen his painful tale. Instead, he receives insults, scolds, and ridicules. Finally, in the stable of his miserable boarding house Iona pours out the sorrowful story to his faithful horse.

It is a dismal story of everyday life but full of human cruelty and senselessness. Human indifference to other people, loneliness, and boredom have been presented as the bedrocks of the old and poor people's life. The community is totally heartless and cold. It is strange that man can be so deaf, dumb, and blind to the people's suffering around. He can easily share other's joy but not even a single instance of sadness. Man is, thus, not only selfish but also dehumanized.

Even more;

When Maxim Gorky heard about the sad demise of his grandmother he wanted to tell somebody about her, but found no one. Then he connected his condition with 
Chekhov's Iona, "Many years later, when he read Chekhov's "wonderfully true story" "Misery," Gorky recalled those days of agony and regretted that he had had neither a dog nor a horse at his side, and that he had not shared his grief with the rats with which he was "on friendly terms" in the bakery where he worked." (Patrick 666)

\section{Bangdel's Novella Langadako Sathi}

A cripple-man makes his living by begging on the streets of Darjeeling and passes the night in a miserable deserted shed. He is completely lonely and has no one in the world. Meantime, a street-dog arrives to become his friend. Soon, they become close mates and start begging, eating, and sleeping together. They grow fond of each other. They experience numerous humiliation, teasing, hitting etc. from the city-folks and school children who insult Langada as a crawling bear. One day, surprisingly, the dog disappears and the cripple-man desperately searches every lane of the town. He is troubled by heavy rain and in the dark night takes shelter on the veranda of a sleeping house. The owner grows suspicious, and despite Langada's humble requests forcefully drags him down through the ladder steps. Next morning the dying protagonist meets his true friend in front of a temple, embraces it, and closes his last eyes. For a few days the dog desperately moves through the alleys and the shed in search of its inner-heart's friend. After ten months the cemetery watchman reports about the finding of the joint skeletons of a man and a dog in the grave.

It's again a story of poverty, inhumanity, loneliness, and insensitivity. The cripple-man has been residing in the local area for a long time but nobody cares him. People never concern who he is, where he lives, and does he need some help? Instead, they humiliate him. The school children are his greatest enemy who always tease and throw stones on him. Only once he feels an instance of human concern and compassion, that too is from a passing poor coal potter whose charity Langada happily shares with his dog. In sum, the humanity is cold, barren, and almost monstrous.

\section{The Juxtaposition}

There are several parallels between these two works created in distant spatiotemporal locations. Both of them project the marginalized characters' special relationships to their companion animals. Iona has a female horse whereas Langada's mate is a male dog. Both of them are significant domestic animals-very sensible among species and human-trained.

These stories have adopted the approach of realism in the presentation of plot, setting and dialogue. Moreover, there is a unity of lyricism and realism. Both of the events are tragic and also pessimistic. The protagonists witness much common suffering in their respective places. A thundering pain grips the heart of both protagonists and their fellow animals. Their lives are so strangely twisted that it is unbearable, full of everlasting suffering and degradation. Main cause of their suffering and pessimism is the people's lack of sensitiveness, and inhumanity to the grief of others. 
The role expected from human members of the society has not been fulfilled. Moreover, it is performed in a reversed way with indifference, insult, and cruelty. The gap, therefore, has been fulfilled by the animals. They have come to replace human role by being friends, interlocutors, and healers. Iano's horse, though tired after hard work, listens the detail narration of its master as if it understands the human language. Langada has friendship with the dog, but the dog has a supreme attitude of friendliness towards its mate. The dog here displays a higher level of conditioning and commitment. But, unfortunately, it has become an scapegoat. Anyway, the dog and the horse here are upheld as the representatives of all non-human animals.

\section{Why Animals in Literature?}

The broad subject of human-animal studies has been ever-expanding in literary landscapes. Such human-animal interface has been growing because thoughtful persons have started to see no line of control that divides all humans and all animals. The new idea is that fundamentally man and animal are one and the same. Likewise, the decline of the false human-animal binary has increased a theoretical interest in "animality." As more innovative works on $\mathrm{HAB}$ are being produced more theories and responses to the discourse of animality have developed. Reasons for the literary representation of animals can be justified according to a scholar as; "Animals make two important contributions to human spiritual development. First, relationships with animals help people to recognize the interconnectedness of all life; this awareness is the foundation of compassion. Second, experiences with animals offer lessons for living in right relationship with others" (Faver, web). Indeed, man can attain awareness and moral lessons by maintaining a friendly relationship with the fellow-animals.

Human civilization has always received assistance from animals as the sources of food, clothing, labor, warship, friendship among others. So, animals have been awarded significant space in religions and rituals too. With reference to Rig Veda the three archeologists observe that "Many ancient people assumed they would encounter dogs in the afterworld. . . . dogs were spiritual escorts to the after life..." (Lobell 35). Similarly, in recent times, dogs have been used for reading therapy and medical or nursing therapy purposes. Therefore, a deep understanding of animal role is essential for analyzing any culture and civilization. Bedekar et. al. clarify the importance of animal through their widespread representation in art and literature, "Right from prehistoric times, humans have left evidences of their interaction with animals; in form of depiction of animal motifs in rock art, graffiti marks, painting, clay models, coins, sculptures and different forms of art, and literature" (Bedekar 207). Out of these animal representations too horse and dog have received more dignified status, and pet status respectively. Obviously, literature is one of those significant canvases where one can read the painting that displays human motives associated with animals.

Prior to man did, it was the dog who chose man as his appropriate companion even though it is a friendship without equality. Schaub, in this connection, quotes Borjesson that "dogs were our companions before we were organized or civilized 
enough to imagine creating them. They began to keep us company long before any other domesticated plant or animal" (83). However, Schaub further comments, this is a relation of friendship, not of friendliness. Friendship involves demanding practice whereas friendliness is a disposition. Such archeological, behavioral, and literary representations of $\mathrm{HAB}$ has given ample space to the related philosophical and theoretical inquiry.

\section{Standpoint Theory to Animal-Standpoint Criticism}

Standpoint Theory focuses on identifying and articulating the point of view or standpoint of any silenced and oppressed group in the society. George Lukacs is the formal initiator of this doctrine, specifically his work History and Class Consciousness. But for the purpose of this presentation I largely depend on this school of criticism's 2011 leading essay "Aestheticizing Animal Cruelty" by Josephine Donovan (College Literature 38.4. Pub. by The Johns Hopkins University Press).

Most of the fiction writers imagine and express the perspectives of their invented human characters, but largely they ignore such responsibility for the fictional animal characters. In almost all of the canonical literary works animals have been used as tools to comment on human condition. Shelley's skylark, Keats's nightingale, Hopkins's falcon all are just used as ladder having little to do with actual birds. This school, similarly, loathes literature where animals stand for various human qualities; lion for courage, lamb for innocence, bee for industriousness, dog for obedience and so on. This commonsense view ultimately encourages anthropomorphism. Therefore, animalstandpoint critics intervene into this lacking space.

This school of criticism regards animals as subjects, not passive objects; similar to their human counterparts, not inferior beings. Furthermore, "they are individuals with stories/biographies of their own, not undifferentiated masses; that they dislike pain, enjoy pleasure; that they want to live and thrive; that in short they have identifiable desires and needs, many of which we human animals share with them" (Donovan 204). Unfortunately, majority of literary works which have employed animal characters have not identified them as separate individuals with their own history and present.

\section{Against the Use of Animal as Vehicle}

Animal standpoint criticism opposes the use of animal metaphor in art where animal pain is explored for aesthetic effect. It is not morally justifiable to symbolize the protagonist's agonized mental state through the torture and death of animals. Consequently, the real suffering of animals is overshadowed. Donovan explains; "The circumstantial realities of the animals themselves are largely ignored so that the perceived pathos of their condition may be used to illustrate the mental state or moral condition of the humans. In short, the moral reality of the animals' suffering is overridden in the interest of creating an aesthetic effect" (206). In metaphorical comparison, indeed, the subject is tenor and the vehicle is just an object. Thus, tenor elides the vehicle, i.e. human anxiety overrules that of the animal. The tendency 
encourages the projection of animals just as embellishments or trivial tropes. Such practice is similar to parasitical and cannibalistic conduct where one is the victim and the benefit goes to the victimizer. This conduct even authenticates the violent hierarchy that animals can be used to meet the human needs as they are primary and the animals secondary.

This sort of figurative projection may console the anthropocentric viewpoints with aesthetic satisfaction, but the independent identity of the animal is sacrificed. To those who sympathize the animals, their sacrifice cannot work as a catharsis to human agony. However, most of the literary works suffer from this tendency. On the other hand, animal-standpoint critics admire literary works that present animals in their subjective form and that respect them as real beings. Such writing is honored as 'vegetarian discourse,' where animals are not merely vehicles to reflect human conditions. Rather, animals are of significant value in their own rights and their viewpoint is no longer repressed. This sort of discourse discourages the use, abuse, and commodification of animals for human advantage.

Animal Ethics Theory also agrees with the standpoint theory in some aspects; Animals enter the picture as beings capable of sensation and perception, of experience and suffering, of interaction with each other and with humans. This individualist turn does not in itself commit authors to accepting the premise that some animals are persons. Nor does it commit them to species egalitarianism, i.e. the idea that all species are owed equal moral consideration. ...

The great innovation of Animal Ethics lies in directing attention to individual animals' pain and suffering, thereby promoting the paradigm shift away from functionalist anthropocentrism as well as holistic environmentalism, yet at the cost of narrowing down academic interest to the promotion of animal well-being. (Ahlhaus 8-10)

\section{Redrawing the "Misery," and "Langadako Sathi"}

Domestic animals and pets are ancient as well as modern companions to human beings. Therefore, they have appeared in art and literature of every era and culture. However, in recent writings they either appear in new identity of human-animal bond or the writings themselves receive a new critical outlook. In the same manner two classical fictional works of HAB have been reexamined through the lenses of recent rights, and ethics theories.

Generally, both works are commendable that they have employed animals not just as human friends but true friends instead of human ones. The inclusion of inseparable entity of human civilization - animal world - is praiseworthy. Moreover, the works reveal an affirmative understanding of animal role. Yet, there exist some crucial questions regarding the empowerment or repression of the species. Apparently, individual identity of the animals has been severely repressed. Neither Chekhov nor Bangdel comments anything about the history, kinship, and relations of the horse and the dog. They have arrived to their masters or human friends just out of the blue. There 
is little bit of action and change in the dog but the horse is completely ignored like a puppet of a baby. Thus, the animals are devoid of their individuality, active role play, preference, and considerable character development.

Obviously, the works do not present human and animal as equal and one; there are several instances of a violent hierarchy. For example, it is not Langada who chooses to befriend the dog but it's vice versa. The animal has offered friendliness, a selfless disposition whereas man is making friendship where there is some desire, some expectation. And, it is because of unselfish friendliness of the dog, probably, the souls of Langada and the dog may reach to the heaven together with the escorting of the latter as mentioned in the Rig Veda.

Mere inclusion but a lack of active participation ultimately enhances anthropocentrism. Both Iona's horse and Langada's dog are presented as inferior to their human counterparts. The horse has not been identified with some desire of its own as Iona has. The living horse exists just like a statue. The old age, weak body, loneliness, and helplessness of the horse intensify such conditions of the cab driver. Likewise, the dog has been presented as inferior being that can eat dirty food from the drains which even a hungry beggar is unable to do. Though Langada dies prior to the dog, the reported death of the dog after ten months intensifies the pathetic life, inhuman treatment, and doomed condition of the beggar. Readers are made to weep not for the dog but for the man. Thus, the animals have not received a considerable attention as subjects. They have been objectified to qualify the human condition. Their feelings and experiences function as vehicle to tenor, i.e. human experiences. None of the works has escaped the maze of the metaphors which paralyze and oppress the full recognition of the animal figures.

The anthropocentric attitude ultimately enhances the abuse and commodification of animals. A good example of the use and abuse of animals for aesthetic human pleasure is, thus, prevalent in Chekhov's and Bangdel's works. To intensify the man's loneliness and agony the animals have been forcefully turned into scapegoats. Their individuality, preference, desire etc. have been deliberately eclipsed-deadenedexploited-discarded. Such treatment of animal life simply maintains the ideology of speciesism - the value that animals are subservient to humans. For this reason readers, critics, and indeed the authors themselves appear ignoring the reality of an animal's suffering and making them only a passive object of the metaphor. 


\section{Works Cited}

Ahlhaus, Svenja, and Peter Niesen. "What is Animal Politics? Outline of a New Research Agenda." Historical Social Research 40 (2015): 7-31.

Altman, Joanne. "The Human/Avian BOND." AAV Today 2.3 (1988): 143-45.

Bangdel, Lain Singh. Langadako Sathi. 1951. Kathmandu: Ratna Pustak, 2011.

Bedekar, Gauri, P. P. Joglekar, and Shripad Bhat. "Human-Animal Interaction in Ancient Indian Society (1500 B.C.-300 A.D.): A Study Through Correlation of Archeological and Literary Sources." Bulletin of the Deccan College Research Institute 76 (2016): 207-211.

Chekhov, Anton. "Misery." Web.

Faver, Catherine A. "Seeking Our Place in the Web of Life: Animals and Human Spirituality." 2009. Web. 15 Dec. 2018.

Lobell, Jarrett A, Eric A. Powell, and Paul Nicholson. "More than Man's Best Friend." Archaeology 63. 5 (2010): 26-35.

McHugh, Susan. "Literary Animal Agents." PMLA 124. 2 (2009): 487-95.

Patrick, George Z. "Chekhov's Attitude towards Life." The Slavonic and East European Review 10.30 (1932): 658-68.

Schaub, Diana. "Dog's Best Friend." The New Atlantis 38 (2013): 81-91. 